\title{
A Satellite Heterogeneous Network Selection Algorithm Combining AHP and TOPSIS
}

\author{
Long Yang \\ Institute of Communication Engineering, PLA University of \\ Science and Technology, Nanjing, 210007, China \\ yang45544941@163.com
}

\begin{abstract}
Against the satellite heterogeneous network optimal selection problem, in this paper we propose a network selection algorithm based on the Analytic Hierarchy Process (AHP) method and the Technique for Order Preference by Similarity to an Ideal Solution (TOPSIS) method. The algorithm considers the parameters that may affect the network selection like quality of business services, user preferences, network load, and so on. The use of AHP is to calculate the weights of various parameters, and TOPSIS is used to obtain the final access network ranking. The simulation results verify the correctness and validity of the algorithm.
\end{abstract}

Index terms-Satellite Heterogeneous Network, Network Selection, AHP, TOPSIS

\section{INTRODUCTION}

With the satellite communication technology developing rapidly, satellite communications have multiple systems, each system is composed by a variety of Network Department. Multi-track, multi-satellite, multi-band, multi-institutional network coexistence are characteristics of the satellite communication system. The direction of development of satellite communication is to achieve any time, any place, any person in effective communication. In the environment of the satellite heterogeneous network, how users solve the Always Best Connected [1] problem according to their own needs and the network characteristics, has become a hot issues in recent years.

At present, there are many multi-attribute decision-making algorithms. In [2], depending on the quality of service requirements of different business, a network selection algorithm based on the signal strength is proposed. In [3], the algorithm used the received signal strength, network throughput and user mobility rate as the judgment parameters, but ignores the factors such as user preferences. In [4], a network selection algorithm based on the network cost which is described as a linear combination of various factors is proposed, but the weights fixed. In [5], M. Pande designed a heterogeneous network options based on throughput optimization, to maximize system throughput as a criterion for network selection decisions. In [6][7][8][9], factors affecting the communication like user preferences, signal strength and QoS are quantifiable indicators, using analytic hierarchy process to establish a network selection model of each factor and calculating the weight, then get the total membership, which determine the optimal network.

\author{
Daoxing Guo \\ Institute of Communication Engineering, PLA University of \\ Science and Technology, Nanjing, 210007, China
}

In this paper, we propose a network selection algorithm that combines the Analytic Hierarchy Process (AHP) [10] method and the Technique for Order Preference by Similarity to an Ideal Solution [11] method. The algorithm choose the best network by taking the different requirements of quality of service for different business, user preferences, network load, network anti-jamming performance into account, to provide users with quality services, efficient use of network resources.

\section{NETWORK SELECTION ALGORITHM}

The satellite heterogeneous network selection algorithm takes the network parameters (such as anti-jamming performance, QoS parameters, network load, security) and user preferences in account when choosing the most suitable network for the current business.

\section{A. AHP method}

AHP method is a qualitative and quantitative method to analysis Multi Attribute Decision Making (MADM) problem. The method consists of the following steps:

Step 1- Construction of hierarchical structure of network selection: According to the factor that affect network selection, the hierarchical structure of network selection is constructed as Figure 1. The user preference is determined based on the jam exist in the current environment.

Step 2- Construction of judgment matrix: In each level, every two decision factors $(\mathrm{i}, \mathrm{j})$ are compared according to their levels of influence to network selection. The value of the comparison results $\mathrm{a}_{\mathrm{ij}}$ is shown in 错误! 未找到引用源。. The judgment matrix $\mathrm{A}=\left[\mathrm{a}_{\mathrm{ij}}\right]$, where $a_{i j}>0, a_{i j}=1 / a_{i i}, a_{i i}=1$.

Step 3- Normalization and Calculation of the relative weights: The relative weights are calculated by the right eigenvector ( $w$ ) of matrix A corresponding to the largest eigenvalue $\left(\lambda_{\max }\right)$, using the square root method.

Calculate the product of matrix elements of each row of the judgment matrix:

$$
M_{i}=\prod_{i=1}^{n} a_{i},(i=1,2, \cdots n)
$$

Calculate the $\mathrm{n}^{\text {th }}$ root of $\mathrm{M}_{\mathrm{i}}$ :

$$
\bar{w}_{i}=\sqrt[n]{M_{i}},(i=1,2, \cdots, n)
$$

Normalize the vector $\bar{W}=\left[\bar{w}_{1}, \bar{w}_{2}, \cdots, \bar{w}_{n}\right]^{T}$ : 


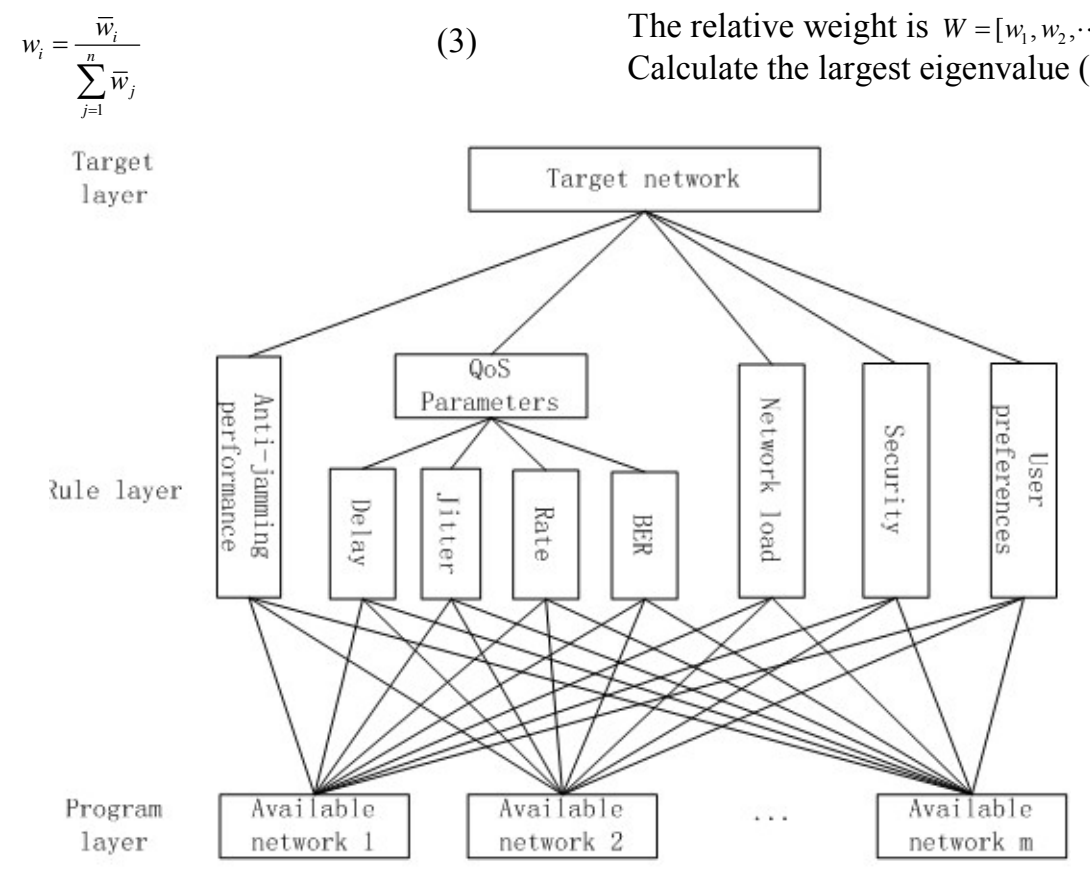

Figure 1 the hierarchical structure of network selection

Table 1 value of $a_{i j}$

\begin{tabular}{c|c|c|c|c|c|c}
\hline$a_{i j}$ & 1 & 3 & 5 & 7 & 9 & $2,4,6,8$ \\
\hline Definition & $\begin{array}{c}\text { Equal } \\
\text { importance }\end{array}$ & $\begin{array}{c}\text { Moderate } \\
\text { importance }\end{array}$ & $\begin{array}{c}\text { Strong } \\
\text { importance }\end{array}$ & $\begin{array}{c}\text { Very strong } \\
\text { importance }\end{array}$ & $\begin{array}{c}\text { Extreme } \\
\text { importance }\end{array}$ & $\begin{array}{c}\text { Intermediate } \\
\text { values }\end{array}$ \\
\hline
\end{tabular}

$$
\lambda_{\max }=\frac{\sum_{i=1}^{n}(A W)_{i}}{\sum_{i=1}^{n} w_{i}}
$$

Step 4-Consistence check: The judgment matrix is subjective, so it requires a Consistence check. We use the ratio of consistency index(CI) and the consistency ratio (RI) as the standard, where

$$
C I=\frac{\lambda_{\max }-n}{n-1}
$$

The ratio is called consistency ratio (CR). If $\mathrm{CR}<0.1$, the matrix has acceptable consistency, otherwise reconstruct the judgment matrix.

Step 5- Determine the final weight of all factor.

\section{B. TOPSIS method}

The Technique for Order Preference by Similarity to an Ideal Solution (TOPSIS) method is an effective multi-attribute decision making method. It need construct multi-attribute decision-making the positive ideal solution and the negative ideal solution. The options should be as close as possible to the positive ideal solution, as far as possible away from the negative ideal solution. The method consists of the following steps:

Step 1- Construct the decision matrix: We assume that in network selection there are $\mathrm{m}$ attributes $\left(\mathrm{G}_{\mathrm{i}}\right)$ should be considered and $\mathrm{n}$ optional network $\left(\mathrm{N}_{\mathrm{i}}\right)$. The value of attribute $\mathrm{G}_{\mathrm{j}}$ of the network $\mathrm{N}_{\mathrm{i}}$ is $\mathrm{a}_{\mathrm{ij}}$, then $\mathrm{A}$ is

$$
\begin{aligned}
& \begin{array}{llll}
G_{1} & G_{2} & \cdots & G_{m}
\end{array} \\
& A=\underset{N_{2}}{N_{2}} \begin{array}{c}
N_{n} \\
N_{n}
\end{array}\left[\begin{array}{cccc}
a_{11} & a_{12} & \cdots & a_{1 m} \\
a_{21} & a_{22} & \cdots & a_{2 m} \\
\vdots & \vdots & \ddots & \vdots \\
a_{n 1} & a_{n 2} & \cdots & a_{n m}
\end{array}\right]
\end{aligned}
$$

Step 2- Normalize decision matrix: Normalize decision matrix A to $\mathrm{B}$, the normalized value of $b_{\mathrm{ij}}$ is computed as

$$
b_{i j}=\frac{a_{i j}}{\sqrt{\sum_{i=1}^{m} d_{i j}^{2}}} \quad i=\{1,2 \cdots, m\}, j=\{1,2 \cdots, n\}
$$

Step 3- Construct the weighted normalized decision matrix: The weighted normalized decision matrix is constructed by multiplying each element $b_{i j}$ with its associated weight $\mathrm{w}_{\mathrm{j}}$, and the weight is got by AHP

$$
\mathrm{c}_{\mathrm{ij}}=\mathrm{b}_{\mathrm{ij}} \mathrm{w}_{\mathrm{j}}
$$

Step 4- Construct the positive and negative ideal solutions: The positive and negative ideal solutions, $\mathrm{N}^{+}$and $\mathrm{N}^{-}$can be defined as:

$$
\begin{aligned}
\mathrm{N}^{+} & =\left(c_{1}^{+}, c_{1}^{+}, \cdots, c_{m}^{+}\right) \\
& =\left\{\left(\max _{j}\left(c_{i j}\right) \mid j \in I_{b}\right),\left(\min _{j}\left(c_{i j}\right) \mid j \in I_{b}\right)\right\}
\end{aligned}
$$




$$
\begin{aligned}
\mathrm{N}^{-} & =\left(c_{1}^{-}, c_{1}^{-}, \cdots, c_{m}^{-}\right) \\
& =\left\{\left(\min _{j}\left(c_{i j}\right) \mid j \in I_{b}\right),\left(\max _{j}\left(c_{i j}\right) \mid j \in I_{b}\right)\right\}
\end{aligned}
$$

where $I_{b}$ is the set with the benefit criteria, and $I_{c}$ is the set with the cost criteria.

Step 5-Calculate the distance and Relative Closeness: The distance of each alternative from the ideal and the negative ideal solution is given

$$
\begin{aligned}
& d_{i}^{+}=\sqrt{\sum_{j=1}^{m}\left(c_{i j}-c_{j}^{+}\right)^{2}} \\
& d_{i}^{-}=\sqrt{\sum_{j=1}^{m}\left(c_{i j}-c_{j}^{-}\right)^{2}}
\end{aligned}
$$

Table 2
The relative closeness is defined to determine the relative closeness of each alternative $\mathrm{Ni}(\mathrm{i}=1,2, \cdot \cdot, \mathrm{n})$ from the ideal solution. It is expressed as

$$
C_{i}=\frac{d_{i}^{-}}{d_{i}^{-}+d_{i}^{+}}
$$

Step 6- Select the network: The descending order of $\mathrm{Ci}$ is the order of the pros and cons of network selection.

\section{E SIMULATION AND RESULT ANALYSIS}

\section{A. Simulation environment}

We assume that terminal is in the environment which is covered by 6 network $\left\{N_{1}, N_{2}, N_{3}, N_{4}, N_{5}, N_{6}\right\}$ that can be available for access. $\mathrm{N}_{1}$ and $\mathrm{N}_{2}$ are narrowband network, $\mathrm{N}_{3}$ and $\mathrm{N}_{4}$ are broadband network, $\mathrm{N}_{5}$ and $\mathrm{N}_{6}$ are anti-jamming network. Network shown

\section{in}

Table 2 Network parameters

\begin{tabular}{|c|c|c|c|c|c|c|c|}
\hline & $\begin{array}{c}\text { Anti-jamming } \\
\text { performance }\end{array}$ & $\begin{array}{c}\text { Delay } \\
(\mathrm{ms})\end{array}$ & $\begin{array}{c}\text { Jitter } \\
(\mathrm{ms})\end{array}$ & $\begin{array}{c}\text { Rate } \\
(\mathrm{Mbps})\end{array}$ & $\begin{array}{c}\text { BER } \\
\left(10^{-4}\right)\end{array}$ & $\begin{array}{c}\text { Network } \\
\text { Load }\end{array}$ & $\begin{array}{c}\text { Security } \\
\text { level }\end{array}$ \\
\hline $\mathrm{N}_{1}$ & 0 & 270 & 40 & 0.1 & 2 & $1 / 10$ & 7 \\
\hline $\mathrm{N}_{2}$ & 0 & 270 & 40 & 0.1 & 2 & $1 / 2$ & 8 \\
\hline $\mathrm{N}_{3}$ & 0 & 400 & 60 & 2 & 3 & $1 / 10$ & 6 \\
\hline $\mathrm{N}_{4}$ & 0 & 400 & 60 & 2 & 3 & $1 / 2$ & 7 \\
\hline $\mathrm{N}_{5}$ & 1 & 500 & 50 & 0.1 & 1 & $1 / 10$ & 8 \\
\hline $\mathrm{N}_{6}$ & 1 & 500 & 50 & 0.1 & 1 & $1 / 2$ & 9 \\
\hline
\end{tabular}

The value of user preferences is determined according to the type of the business and whether there is jam in the environment. If jam doesn't exist in environment, low-speed business's user preferences to narrowband, broadband, antijamming network are 1,0.5,0.2, while high-speed business's user preferences to narrowband, broadband, anti-jamming network are $0.5,1,0.2$. If jam exists in environment, business's user preferences to narrowband, broadband, antijamming network are $0,0,1$.

Assume that the business can afford the maximum bit error rate, delay, jitter, respectively, $10 \times 10-4 、 600 \mathrm{~ms} 、 100 \mathrm{~ms}$, low-speed business rate is less than $0.1 \mathrm{Mbps}$, high-speed business rate is 0.07 to $0.2 \mathrm{Mbps}$.

\section{B. Simulation results analysis}

First, jam doesn't exist in environment, low-speed voice business communicates in $0-5 \mathrm{~min}$, and high-speed multimedia business communicates in 5-10min. Then jam exists in environment, low-speed voice business communicates in 10$15 \mathrm{~min}$, and high-speed multimedia business communicates in 15-20min.

1 Without jam, the order of importance of low-speed voice business's first layer parameters is business QoS(q), user preferences(u), network load(l), security(s), anti-jamming performance(a), and the order of the second layer parameters is delay(d), jitter(j), rate(r), BER. The relative importance of parameters is shown in Table 3 and Table 4.

Table 3 The relative importance of low-speed voice business's first layer without jam

\begin{tabular}{|c|c|c|c|c|c|}
\hline & $\mathrm{a}$ & $\mathrm{q}$ & $\mathrm{l}$ & $\mathrm{s}$ & $\mathrm{u}$ \\
\hline $\mathrm{a}$ & 1 & $1 / 9$ & $1 / 5$ & $1 / 3$ & $1 / 7$ \\
\hline $\mathrm{q}$ & 9 & 1 & 4 & 6 & 2 \\
\hline 1 & 5 & $1 / 4$ & 1 & 2 & $1 / 2$ \\
\hline $\mathrm{s}$ & 3 & $1 / 6$ & $1 / 2$ & 1 & $1 / 4$ \\
\hline $\mathrm{u}$ & 7 & $1 / 2$ & 2 & 4 & 1 \\
\hline
\end{tabular}

Note: $\mathrm{CR}=0.0164<0.1$

Table 4 The relative importance of low-speed voice business's second layer

\begin{tabular}{|c|c|c|c|c|}
\hline & $\mathrm{d}$ & $\mathrm{j}$ & $\mathrm{r}$ & BER \\
\hline $\mathrm{d}$ & 1 & 2 & 7 & 9 \\
\hline $\mathrm{j}$ & $1 / 2$ & 1 & 5 & 7 \\
\hline $\mathrm{r}$ & $1 / 7$ & $1 / 5$ & 1 & 2 \\
\hline BER & $1 / 9$ & $1 / 7$ & $1 / 2$ & 1 \\
\hline
\end{tabular}

Note: $\mathrm{CR}=0.0153<0.1$ 
Using AHP method, weights of anti-jamming performance, delay, jitter, rate, BER, network load, security, user preferences are :

$$
\mathrm{W}_{1}=\left[\begin{array}{llllll}
0.0353 & 0.2538 & 0.1549 & 0.0370 & 0.0226 & 0.1455
\end{array}\right.
$$$$
\left.\begin{array}{lll}
0.0799 & 0.2709
\end{array}\right]
$$

2 Without jam, low-speed business's user preferences to narrowband, broadband, anti-jamming network are 1, 0.5, 0.2. Using TOPSIS method, the relative closeness of every network are:

\section{$\mathrm{T}_{1}=\left[\begin{array}{llllll}0.8175 & 0.6666 & 0.4784 & 0.3445 & 0.3260 & 0.1632\end{array}\right]$}

So, $\mathrm{N}_{1}$ is the best choice for network selection.

Without jam, the order of importance of high-speed multimedia business's first layer parameters is business QoS(q), network load(l), user preferences(u), security(s), antijamming performance(a), and the order of the second layer parameters is rate(r),delay(d), jitter(j), BER. The relative importance of parameters is shown in Table 5 and Table 6.

.Table 5 The relative importance of high-speed multimedia business's first layer without jam

\begin{tabular}{|c|c|c|c|c|c|}
\hline & $\mathrm{a}$ & $\mathrm{q}$ & $\mathrm{l}$ & $\mathrm{s}$ & $\mathrm{u}$ \\
\hline $\mathrm{a}$ & 1 & $1 / 9$ & $1 / 7$ & $1 / 3$ & $1 / 4$ \\
\hline $\mathrm{q}$ & 9 & 1 & 2 & 7 & 4 \\
\hline 1 & 7 & $1 / 2$ & 1 & 5 & 2 \\
\hline $\mathrm{s}$ & 3 & $1 / 7$ & $1 / 5$ & 1 & $1 / 2$ \\
\hline $\mathrm{u}$ & 4 & $1 / 4$ & $1 / 2$ & 2 & 1 \\
\hline
\end{tabular}

Note: $\mathrm{CR}=0.0166<0.1$

Table 6 The relative importance of high-speed multimedia business's second layer

\begin{tabular}{|c|c|c|c|c|}
\hline & $\mathrm{d}$ & $\mathrm{f}$ & $\mathrm{r}$ & BER \\
\hline $\mathrm{d}$ & 1 & 2 & $1 / 5$ & 4 \\
\hline $\mathrm{j}$ & $1 / 2$ & 1 & $1 / 6$ & 2 \\
\hline $\mathrm{r}$ & 5 & 6 & 1 & 7 \\
\hline BER & $1 / 4$ & $1 / 2$ & $1 / 7$ & 1 \\
\hline
\end{tabular}

Using AHP method, weights of anti-jamming performance, delay, jitter, rate, BER, network load, security, user preferences are :

\section{$\mathrm{W}_{2}=\left[\begin{array}{llllll}0.0364 & 0.0900 & 0.0511 & 0.3047 & 0.0293 & 0.2787\end{array}\right.$ $\begin{array}{ll}0.0729 & 0.1369]\end{array}$}

Without jam, low-speed business's user preferences to narrowband, broadband, anti-jamming network are 1, 0.5, 0.2. Using TOPSIS method, the relative closeness of every network are:

$$
\mathrm{T}_{2}=\left[\begin{array}{llllll}
0.3836 & 0.1263 & 0.8812 & 0.6231 & 0.3746 & 0.1091
\end{array}\right]
$$

So, $\mathrm{N}_{3}$ is the best choice for network selection.

3 When jam exists, demand of network anti-interference performance increases rapidly, so the order of importance of low-speed voice business's first layer parameters is antijamming performance(a), user preferences(u),business QoS(q), network load(l), security(s), and the order of the second layer parameters is delay $(\mathrm{d})$, jitter(j), rate(r), BER. The relative importance of parameters is shown in Table 7 and Table 4.

Table 7 The relative importance of low-speed voice business's first layer with jam

\begin{tabular}{|c|c|c|c|c|c|}
\hline & $\mathrm{a}$ & $\mathrm{q}$ & $\mathrm{l}$ & $\mathrm{s}$ & $\mathrm{u}$ \\
\hline $\mathrm{a}$ & 1 & 4 & 8 & 9 & 2 \\
\hline $\mathrm{q}$ & $1 / 4$ & 1 & 4 & 3 & $1 / 2$ \\
\hline $\mathrm{l}$ & $1 / 8$ & $1 / 4$ & 1 & 2 & $1 / 6$ \\
\hline $\mathrm{s}$ & $1 / 9$ & $1 / 3$ & $1 / 2$ & 1 & $1 / 7$ \\
\hline $\mathrm{u}$ & $1 / 2$ & 2 & 6 & 7 & 1 \\
\hline
\end{tabular}

Note: $\mathrm{CR}=0.0164<0.1$

Using AHP method, weights of anti-jamming performance, delay, jitter, rate, BER, network load, security, user preferences are :

$\mathrm{W}_{3}=\left[\begin{array}{llllll}0.4774 & 0.0787 & 0.0480 & 0.0115 & 0.0070 & 0.0537\end{array}\right.$ $0.04090 .2828]$

4 With jam, low-speed business's user preferences to narrowband, broadband, anti-jamming network are 1, 0.5, 0.2. Using TOPSIS method, the relative closeness of every network are:

\section{$\mathrm{T}_{3}=\left[\begin{array}{llllll}0.0745 & 0.0496 & 0.0638 & 0.0280 & 0.9506 & 0.9252\end{array}\right]$}

So, $\mathrm{N}_{5}$ is the best choice for network selection.

With jam, the order of importance of high-speed multimedia business's first layer parameters is anti-jamming performance(a), user preferences(u), network load(l), business QoS(q), security(s), and the order of the second layer parameters is rate(r), delay(d), jitter(j), BER. The relative importance of parameters is shown in Table 8 and Table 6.

Table 8 The relative importance of high-speed multimedia business's first layer with jam

\begin{tabular}{|c|c|c|c|c|c|}
\hline & $\mathrm{a}$ & $\mathrm{q}$ & $\mathrm{l}$ & $\mathrm{s}$ & $\mathrm{u}$ \\
\hline $\mathrm{a}$ & 1 & 8 & 6 & 9 & 4 \\
\hline $\mathrm{q}$ & $1 / 8$ & 1 & $1 / 2$ & 3 & $1 / 3$ \\
\hline $\mathrm{l}$ & $1 / 6$ & 2 & 1 & 5 & $1 / 2$ \\
\hline $\mathrm{s}$ & $1 / 9$ & $1 / 3$ & $1 / 5$ & 1 & $1 / 7$ \\
\hline $\mathrm{u}$ & $1 / 4$ & 3 & 2 & 6 & 1 \\
\hline
\end{tabular}

Using AHP method, weights of anti-jamming performance, delay, jitter, rate, BER, network load, security, user preferences are :

$\mathrm{W}_{4}=\left[\begin{array}{llllll}0.5699 & 0.0140 & 0.0079 & 0.0473 & 0.0045 & 0.1237\end{array}\right.$ $\begin{array}{lll}0.0336 & 0.1991]\end{array}$

Using TOPSIS method, the relative closeness of every network are: 
$\mathrm{T}_{4}=\left[\begin{array}{llllll}0.1160 & 0.0117 & 0.1310 & 0.0687 & 0.9310 & 0.8688\end{array}\right]$

So, $\mathrm{N}_{5}$ is the best choice for network selection.

The simulation result is shown in Figure 2.

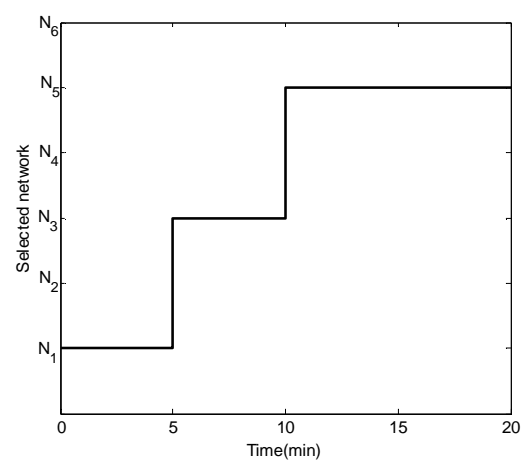

Figure 2 Network selection result

Through above simulation scene, analysis that:

1 Network selection is first to determine whether there is jam in the environment. With jam, the objective function value of the anti-jamming network is significantly higher than other network, because the other networks can't guarantee the reliability of signal transmission. Only the anti-jamming network can be used for communication.

2 Without jam, The main factors affecting the network selection are business QoS and user preference. Low-speed voice business and high-speed multimedia business select narrowband network and broadband network, according to their QoS requirement and user preferences.

3 For the selected same type network, we consider the nework load, make the access probability of low network load network larger than others. It is good for network load balancing, and it can reduce the rate of network congestion.

\section{CONCLUSION}

In satellite heterogeneous network communication, how use choose more suitable network to communicate and meet their own demands is a key technology. The network selection algorithm proposed by this paper makes a best network selection results for users and network, according to different business Qos requirements under different environments and user preferences, and it also take the network load into account to contribute to the network load balancing. The simulation results verify the correctness and validity of the algorithm.

\section{REFERENCES}

[1] E.Gustafsson ,A.Jomsson. Always Best Connected. IEEE Wireless Communication,2003,10(1):49-55.

[2] PARK, H. YOON s, KIM T, et al. Vertical handoff procedure and algorithm between IEEE802.11 WLAN and CDMA cellular network $[\mathrm{C}] / /$ Proceedings of 7 th
CDMA International Conference on Mobile Communications. Seoul:[s.n.],2003:103-112.

[3] A Majlesi, B H Khalaj. An Adaptive Fuzzy Logic Based Handoff Algorithm for Interworking between WLANs and Mobile Networks[c].The 13th IEEE International Symposium.2002,5(5):2246-2451.

[4] T AI-Gizawi, K Peppas, F Lazarakis. Interoperability Criteria Mechanisms and Evaluation of System Performance for Transparently Interoperating WLAN and UMTS-HSDPA Networks[J].IEEE Network,2005,19(4):66-72.

[5] Ylianttila M, Pande M. Optimization scheme for mobile users performing vertical handoffs between IEEE 802.11 and GPRS/EDGE networks[C]. IEEE Globecom, 2001, 6(4): 3439-3443.

[6] Mcnair J, Zhu F. Vertical handoffs in fourth-generation multinetwork environments[J]. IEEE Wireless Communications, 2004, 11(3): 8-15.

[7] Liang L T, Ji Y, Zhang P. A network selection algorithm based on fuzzy analytic hierarchy process in hererogeneous systems[J]. Journal of Beijing University of Posts and Telecommunications, 2007, 30(2): 1-5.

[8] Farooq B, Leung V C M. Automated network selection in a heterogeneous wireless network environment $[\mathrm{J}]$. IEEE Network Magazine, 2007, 21(1): 34-40.

[9] Song Q, Jamalipour A. Network selection in an integrated wireless LAN and UMTS environment using mathematic modeling and computing techniques[J]. IEEE Wireless Communications, 2005, 12(3): 4248.

[10] T.L.Saaty. The Analytic Hierarchy Process ,RWS Publications, Pittsburgh, PA, 1900

[11] C.L> Hwang, K. Yoon, Multiple attribute decision marking: Methods and applications, A State of the Art Survey, New York: Springer Verlag,ISBN:3540105581,1981. 